\title{
Prevalence of Home Storage of Medicines and Associated Factors in Iraq
}

\author{
Sattar J. Abood ${ }^{1}$, Waleed K. Abdulsahib ${ }^{1 *}$, Mohanad Y. Al-Radeef ${ }^{2}$ \\ ${ }^{1}$ Department of Pharmacology, College of Pharmacy, Al Farahidi University, Baghdad, Iraq; ${ }^{2}$ Department Clinical Pharmacy, \\ College of Pharmacy, Tikrit University, Iraq
}

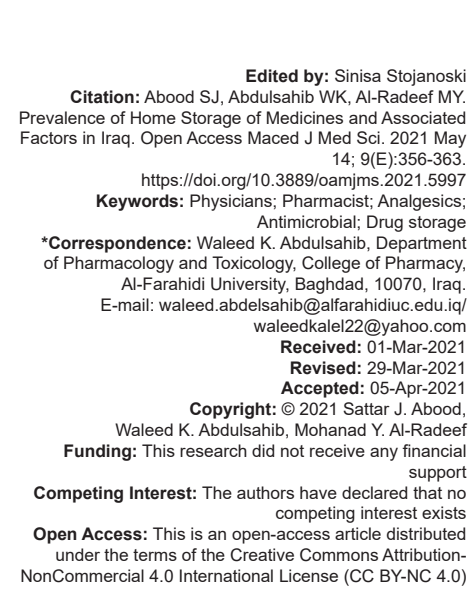

\section{Introduction}

After the Gulf War in 2003, drug trading in Iraq was unregulated and widespread due to the occurrence of many unlicensed drug stores selling non-prescribed drugs. This allows people to store medications and self-medicine at home. Drugs without a prescription, especially antimicrobial agents, have become a practice often encouraged in the Iraqi community [1], [2]. Easy access to medicines has provided a high rate of use of medicines for self-restraint diseases. In addition, unnecessary utilize of drugs may lead to wastage of resources, augmented resistance to infections, serious health hazards, chronic pain, increased adverse drug reactions and interactions, and delays in proper treatment where errors have occurred [3].

By interacting with receptors or enzymes in cells, drug therapy is the most widely utilized intervention in the prevention and treatment of diseases. It is considered to be a part of the larger therapy community. However, ineffective drugs do more harm than good in improving diagnosis and treatment with other health professionals [4]. Pharmaceutical preparations are mainly classified in most countries/regions, whether they can only be purchased by prescription or sold overthe- counter (OTC). The classification of prescription or over-the-counter drugs mainly depends on the safety and effectiveness of the drug and the possibility of abuse by patients [5].

Over-the-counter drugs are defined as effective and safe treatments that are available to the entire population without a prescription. These medicines successfully treat common conditions and allow the consumer to select a safe and effective product [6], [7]. Prescription only medicines defined as drugs prescribed only by physicians or special healthcare professionals [8]. Physicians provide supervision of the patient's status and track the patient's compliance with his or her treatment plan [9]. 
Medicines are held for various reasons in most homes worldwide, including urgent use and the treatment of acute or chronic disorders. These medications are administered by health practitioners or accessed through OTC in the communities. Overthe-counter medication is obtained in high proportion in the home, often used improperly, can remain unused, expired or can be replicated in self-medication, so the risk of self-medication remains increasing in comparison with prescribed medicines [7]. The existence of drugs in the family is a hazard factor for illogical use of drugs, primarily because they are easily available. This fact exposes patients to many adverse drug effects and failure of treatment. People in most communities in developing countries know little about the safety of drugs [10]. The increase in the burden of disease, especially in developing countries, the rapid recovery of the disease, and the desire among communities to receive self-medication has affected the household storage of medicines. The problems with household medicines involve poor storage because conditions such as temperature and humidity are not controlled. This event increases the possibility of drug failure [1]. Due to the absence of the ability to identify expired drugs at home, most people are taking these drugs, which increases the danger of adverse reactions [11]. The main task of controlling the use of drugs used at home is to reduce accidental toxicity, especially for unauthorized users, such as children. The existence of drugs in the family is also related to drug sharing, which constitutes the risk of illegal drug use, and therefore also produces drug resistance [12].

\section{Aim of the study}

Several studies aimed to examine the populations' awareness of household drug storage in developed countries [1], [3], [10]. However, little is known about how citizens in Iraq store their in-home medications. Therefore, this study designed to generate information on the prevalence and factors related to medicines stored at home in the Government of Diyala in Iraq.

\section{Methods}

\section{Study population}

Two hundred subjects from a pharmacy in a private medical center in Diyala Province, Iraq, in July 2019 were selected to participate in this cross-sectional descriptive study. The study period lasted 4 months. The study was approved by the Health Research Ethics Review Board of the College of Pharmacy of Al Farahidi University under number 398A. The purpose of the research was clarified to the study population, confidentiality was assured and written consent was obtained before data collection. The supervisor performed a face-to-face interview with a standardized questionnaire. The participants were fully informed about the goals of the study and specifically informed about where, how, and when to efficiently collect data and how to correctly complete the questionnaire (Table S1). A standardized questionnaire was developed based on available literature. To ensure the quality of the data, a similarly set pre-test questionnaire was conducted on ten subjects before the actual data collection. Interviews were conducted with the head of the household or his partner or any adult willing to provide relevant information. To conduct the research, each participant was provided with detailed information and confidentiality. Participation in the study was voluntary. A structured questionnaire is used, which consists of two parts as shown in Table S1. The first section included data on socio-demographic characteristics (name, age, gender, address, educational level, and occupation). The second part includes questions about the stock of medicines at home, involving the following aspects: Whether they have medicines at home; storage conditions and storage locations; whether these medicines are prescribed by doctors, pharmacists or self-prescribed; the source of these drugs; the common types and dosage forms of these drugs; whether these drugs are currently in use, remaining drugs (used for previous conditions) or backup drugs (reserved for future use); whether they paid attention to the expiry date of these medicines; and whether they exchanged these medicines between the family members and their relatives, friends, or neighbors.

\section{Statistical analysis}

The data were reviewed, sorted, submitted, and analyzed using Microsoft Excel 2010. Continuous variables are represented by mean \pm standard deviation (SD), while discrete variables are represented by quantity and percentage. SPSS version 23 was used for further descriptive analysis.

\section{Results}

\section{Demographic data}

A total of 200 households filled out the questionnaire. The average age of these participants was $42.265 \pm 12.69$ years. Of them, 106 (53\%) were males and 94 (47\%) were females, 148 (74\%) were living in an urban area and $52(26 \%)$ were living in a rural area. Fifteen of them (7.5\%) were illiterate, 35 (17.5\%) completed their primary school, 40 (20\%) completed their secondary school, and 110 (55\%) completed their higher education. These data are shown in Table 1. 
Table 1: Demographic characteristics of participants

\begin{tabular}{lll}
\hline Parameter & & No. $(\%)^{*}$ \\
\hline Age & $42.265 \pm 12.69$ & \\
Gender & Male & $106(53 \%)$ \\
& Female & $94(47 \%)$ \\
Residence area & Urban & $148(74 \%)$ \\
& Rural & $52(26 \%)$ \\
Educational level & Illiterate & $15(7.5 \%)$ \\
& Primary & $35(17.5 \%)$ \\
& Secondary & $40(20 \%)$ \\
& Higher & $110(55 \%)$ \\
\hline${ }^{*}(\mathrm{n}=200)$. & &
\end{tabular}

\section{Prevalence of storing medicines at home}

As shown in Figure 1, all the participants enrolled in this study reported to keep medicines at their homes.

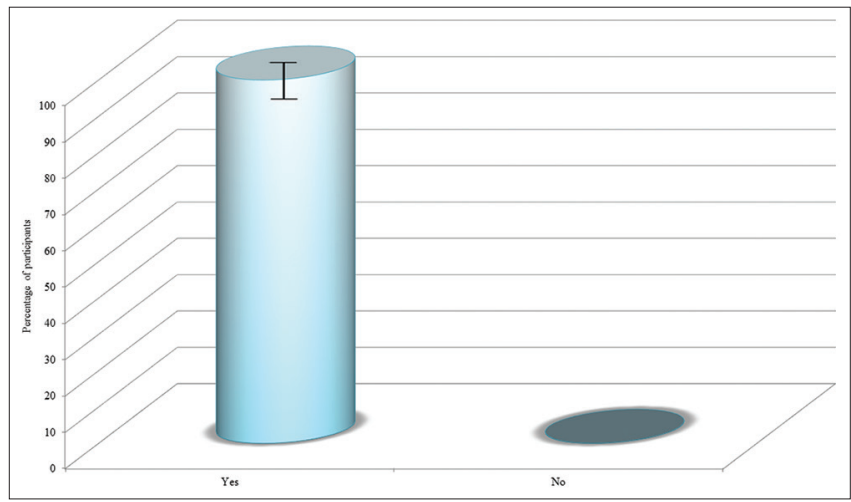

Figure 1: Percentage of participants that stored drugs in this study

\section{Quantities of medicines stored/household}

A total of 2465 storage items were reported in this study. On average, each family has 12.32 kinds of products. The results also show that most households (58\%) leave $6-15$ products at home. These specifics are set out in Figure 2.

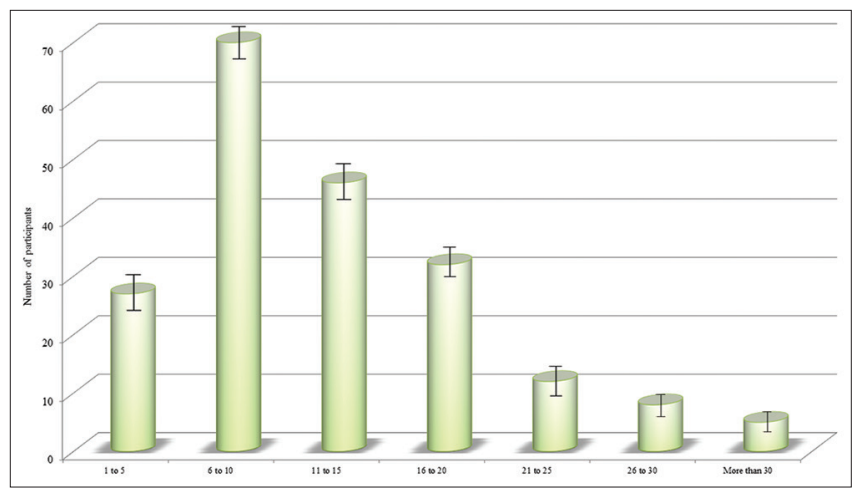

Figure 2: Quantities of medicines stored/household

\section{Storage places of medications}

The places where medications were kept at home are shown in Figure 3 . The refrigerator is the most popular location $(65.5 \%)$, followed by the kitchen counter $(33 \%)$; the remaining medicines are placed on the bedroom/living room table. Not a single head of household puts medicine in the bathroom.

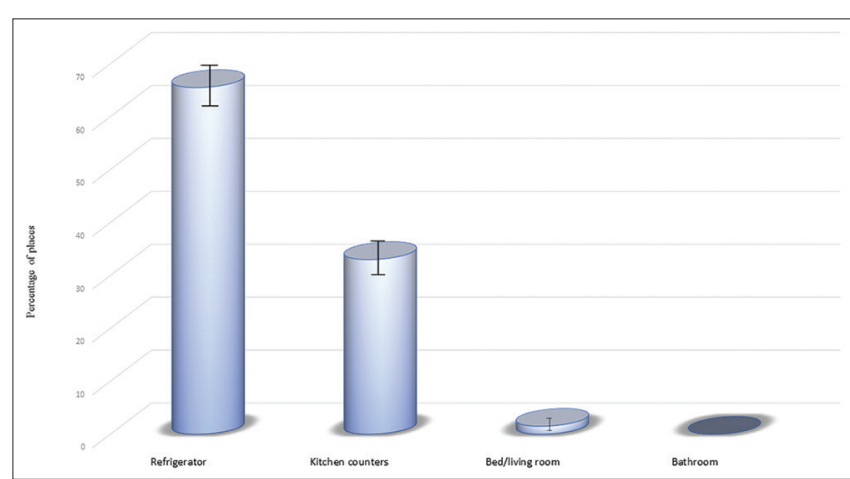

Figure 3: Storage places of medications

\section{Physician and non-physician prescribed} medications

Figure 4 shows medicines prescribed by doctors and medicines not prescribed by doctors, such as self-prescribed medicines or medicines prescribed by a pharmacist, relative, or friend. The majority of the stored drugs were prescribed to the householders by the physicians $(78.5 \%)$, followed by the pharmacists $(11.5 \%)$, self-prescribed $(8 \%)$, and the relatives or friends of the householders $(2 \%)$.

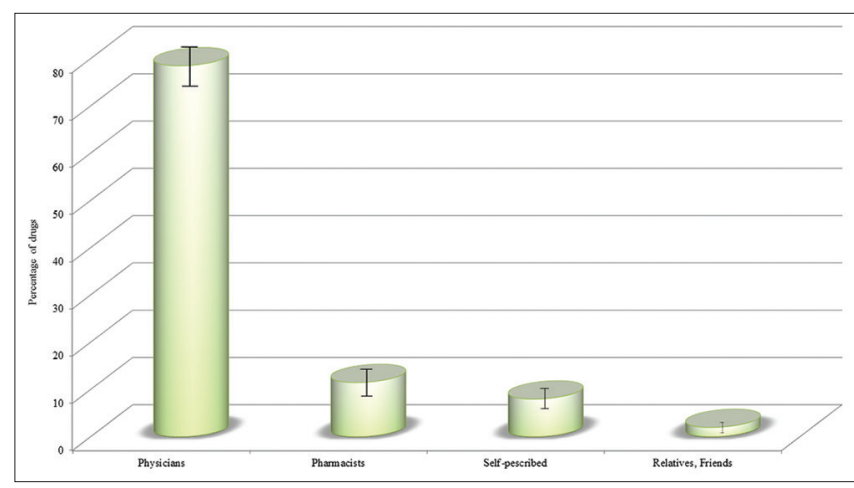

Figure 4: Physician and non-physician prescribed medications

\section{Sources of stored medications}

Figure 5 shows the percentage of drugs in the traditional sources from which households have acquired the drugs. The main source of drugs left at home is private pharmacies $(55.71 \%)$. In contrast with the majority of drug sources, $(32.03 \%)$ government health

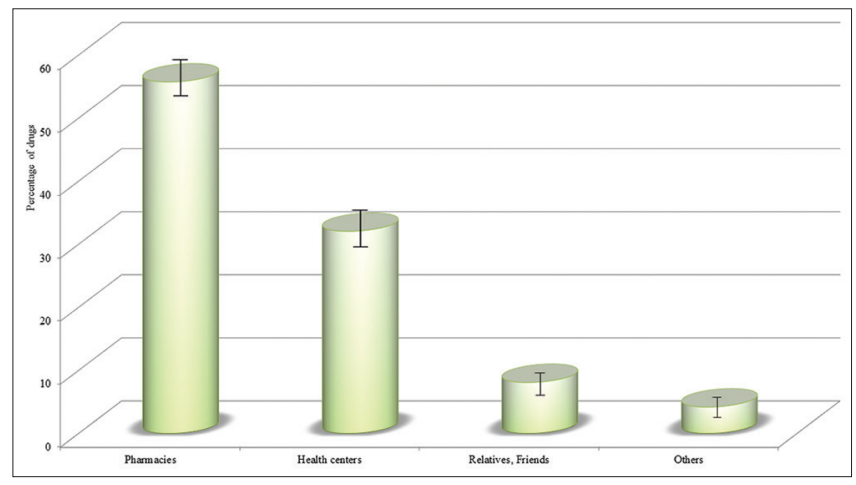

Figure 5: Sources of stored medications 
centers also represented a large number; whereas other sources (friends and shops) were the least popular drug source in this report (8.07 and $4.17 \%$, respectively).

\section{Therapeutic categories of stored medicines}

Figure 6 shows the most commonly reported therapeutic drugs stored at home. Analgesics such as nonsteroidal anti-inflammatory drugs, acetaminophen and its related combinations such as acetaminophen with codeine were the main classes of the drugs that were stored by participants at their home (23.1\%), followed by antimicrobials (antibiotics, antibacterial, and antifungal) and cough mixtures/cold remedies (antihistamines and decongestants) (19.44\% and $17.94 \%$, respectively). Other medicines stored at home include vitamin preparations (9.58\%), antacids (8.36\%), antidiarrheal drugs $(6.86 \%)$, antihypertensive drugs $(5.15 \%)$, and hypoglycemic drugs $(4.72 \%)$.

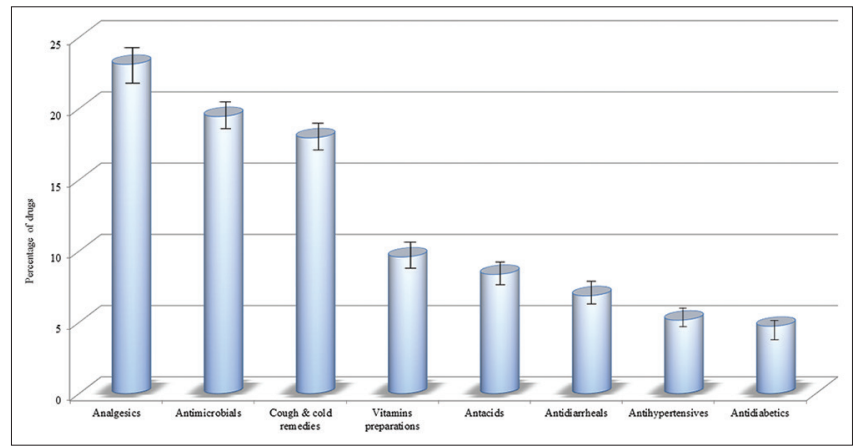

Figure 6: Therapeutic categories of stored medicines

\section{Usage status of currently stored medications}

Figure 7 shows the usage status of the drugs stored by the households at the time of this study. The results show that $43.34 \%$ of these drugs are currently in use, $29.78 \%$ were leftover drugs, and $26.87 \%$ is a standby medicine to be used.

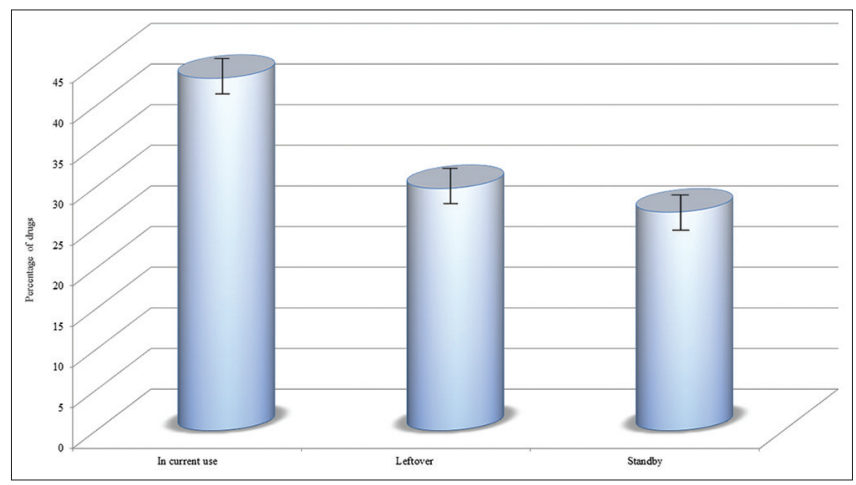

Figure7: The usage status of medication

\section{Expiration date}

Figure 8 represents the level of householders' knowledge of expiration date and the results showed that $82.5 \%$ of these participants knew that their stored

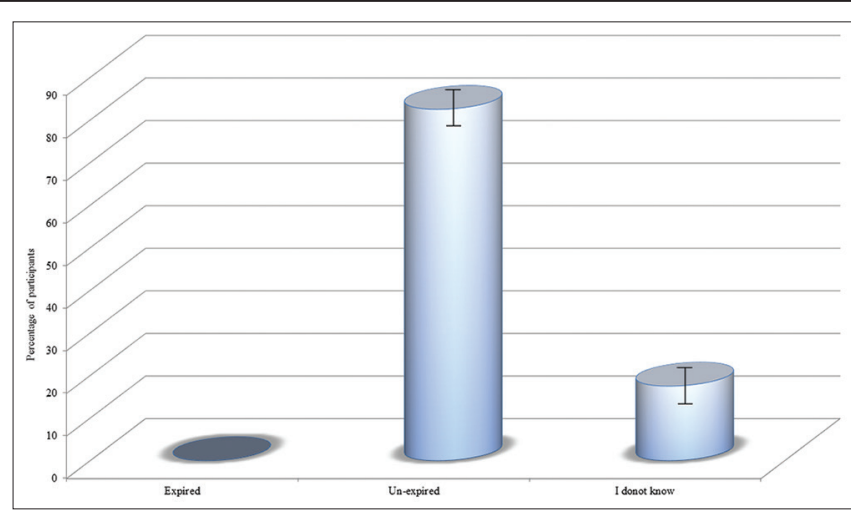

Figure 8: The level of householders' knowledge regarding expiration date

medications were valid to be used (unexpired products); on the other hands, $17.5 \%$ of the households had no idea about the expiration date of these medications.

\section{Dosage form types}

The data presented in Figure 9 showed that the solid dosage forms (tablets and capsules) were the most common formulations presented in the homes of householders enrolled in this study $(21.16 \%$ and $20.95 \%$, respectively), followed by drop preparations for eye, ear, or nose conditions (11.42\%), syrups (10.26\%), ampules/vials (10.05\%), and suppositories (8.88\%).

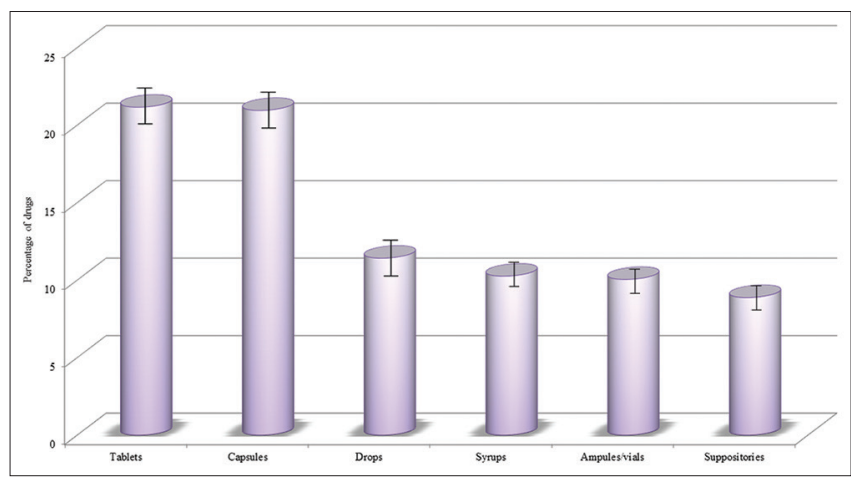

Figure 9: The dosage forms of medication

\section{Sharing stored medicines with others}

In answer to the question related to sharing stored medications with others, nearly one-third (37\%) reported that they shared them with their friends or relatives, while the remaining two-thirds (67\%) were not giving them to others. Figure 10 represents these data.

\section{Discussion}

This research is of great significance to health workers and the entire community because it clarifies the storage of medicines in the home and determines 


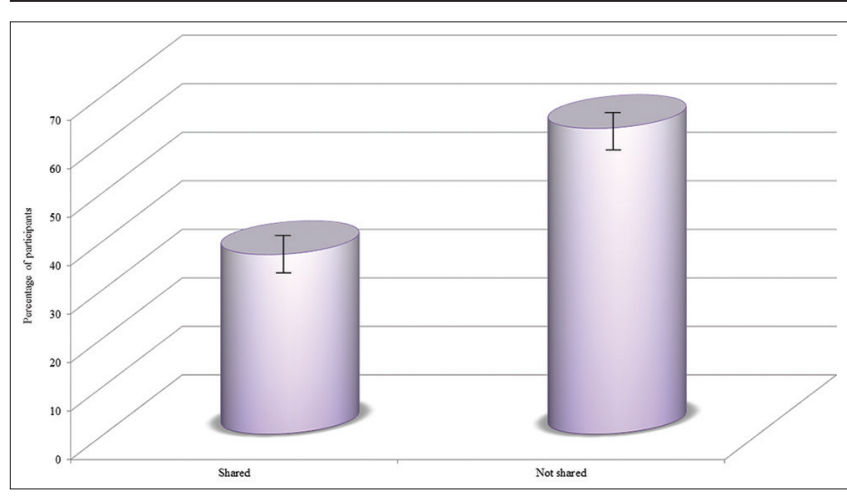

Figure 10: Sharing stored medicines with others

the level of community knowledge about storage in the home, especially in Diyala State, Iraq. The increased use of medicines raises the risk of accumulating medicines at home, both long-term and short-term care [13]. The availability of such medicinal products stored at home is a direct risk factor for inappropriate medicines using behavior such as self-medication by, finally, promoting the use of residues from previous treatments and OTC medicines for symptoms previously experienced [13], continuing to use stored drugs when required, sharing drugs between families, poor adhesion, and consequent enforcement [14].

\section{Prevalence of storing medicines at home}

A total of 200 households from Diyala, Iraq, are included in the study. All of the householders (100\%) enrolled in this study stored drugs at their homes. This finding is comparable to studies conducted in the Islamic Republic of Iran, United Arab Emirates, Sudan, and Basra-Iraq. The Iranian study reported that all the households kept medicines at home [15]. A study conducted in the Emirates reported that only (2\%) of domestic households did not store drugs at home [11]. Research in Sudan shows (97.5\%) that at least one medicine has been stored in the home [3], while the prevalence in Basra-Iraq is similar (94\%) [1]. On the other hand, a study involved the Saudi population showed that $77.66 \%$ of its participants kept drugs at home [14], while studies conducted in Northern Uganda [10] and Northern Ethiopia (9) reported lower prevalence rates of stored drugs than this study as the rates were $(35.1 \%)$ and $(29 \%)$, respectively. Uncontrolled delivery of medicines and the existence of an enormous number of pharmacy outlets without prescription can be due to the high prevalence rates [1]. Similarly, the difference may be due to stricter regulations on the use of essential medicines in other countries [11], and the fact that a large number of people rely on traditional medicine [12]. The prevalence of medicines stored in male households is slightly higher than that of female households. In contrast, Australian women are more likely than men to buy and store medicines at home [13]. In Uganda study found that women are more able to speak about medicines and traditionally are responsible for children's well-being in the family [10]. This difference may be due to the fact that male subjects are the most visited population among Iraqi health-care professionals (pharmacies, hospitals, etc.). The high prevalence of the storage in households of participants in this research, which had attained a minimum primary level of education and above, was stated to have been educated by $92.5 \%$ participants, in line with the findings of Ocan et al. [10]. This may be due to knowledgeable people's growing understanding of healthcare and their desire to be responsible for their health [10].

\section{Medicine's quantities in homes}

The average number of drugs stored in the household reported in this study is per household (12.32). This number is comparable with the average number of medications stored at home reported in Basra-Iraq where the mean number of medications reported per household unit was 14.26 [1] and in Northern Palestine where the mean number of medications reported per household unit was 13.26 [16]. These results show very high difference when compared to studies in other countries such as Qatar and Sudan [3], [5], [10], [12]. This difference in the number of stored drugs may be related to the way the drugs are distributed and obtained. In addition sites, where the use of OTC drugs is practiced other than licensed (authorized) outlets, have been found to lead to the promotion of home drug storage [1]. The prevalence is often affected by socio-economic factors, cultural perceptions, and drug advertisements. Excessive prescriptions, incorrect treatment compliance, treatment modifications after hospitalization, and excessive shipments have resulted in storing the remaining medicines at home, which are some other reasons for storing medicines at home [1]. However, due to the sensitivity of the information, these findings should be treated with caution.

\section{Storage places of medications}

This study shows most families keep medicines in refrigerators. The kitchen counter was the second most frequently used location in this study. This inference is consistent with Foroutan et al. [15]. On the other hand, Kheir et al. contrary to this finding, in Qatar [5], most medicines (50\%) are kept in bedrooms, followed by refrigerators (24.9\%) and living/bathrooms (19\%). Ali et al. in a Malaysian study [17] also recorded that female students tend to store (58.7\%); their medicines are placed in cupboards on the wall shelf (26.6\%). A study in Ethiopia [12] found that the majority of the drugs have been stored in drawers (36\%). The storage of medicines in damp and humid homes, as well as exposure to light or high temperatures, can cause medicines to degrade faster than expected [16], [18]. 
Storing medicines in easily accessible locations is a risk factor for accidental poisoning and suicide attempts in infants. In some countries in the Middle East, it is common to store medicines on top of refrigerators, which prevents children from contacting medicines, while exposing them to the excess heat generated by the equipment and contaminating food when preparing food [13]. Given that it is best to store the medicine in dry and dark place out of reach of kids, and the container is best stored in the container [5], these findings indicate that the storage conditions of the medicine are poor or often dangerous.

\section{Sources of stored medicines}

This study shows that most of the medicines kept in the home were prescribed by doctors. These result consistence's with the previous studies performed by Yousif [3]. However, a study conducted in BasrahIraq showed that the percentage of prescription drugs was low (30\%) [3]. Furthermore, this study shows a private pharmacy is the main source of household storage of medicines, followed by government health centers. These findings strengthened by Jassim study that pointed similar results [3]. On the other hand, the study by Wondimu et al. [12] found that the majority of stored drugs were obtained from hospitals and medical institutions, while pharmacies represent the minor provider of such stored drugs.

\section{medicines \\ Therapeutic categories of stored}

Among the households recorded in the survey, analgesics [19] and antibacterial [20] drugs were the most commonly used drugs. Populations in this study often used these drugs because they described the reasons, such as the need for monthly painkillers and the need for antibiotics with or without cold medicine to treat symptoms of the common cold and flu. This finding is consistent with many studies. For example, Foroutan et al. [15] recorded that analgesics antibiotics are the most popular drug categories in Iran. In the Malaysian study described earlier, analgesic represent the most used medications [17]. In addition, Jassim [1] pointed out in his study that the main drugs stored at home are antibiotics and antipyretic/analgesics. Ocean et al. [10] also pointed out that antibacterial agents and analgesics are the most common drugs in the family.

\section{Usage status of currently stored medications}

This study shows that high percent of stored drugs in are in use, and low percent represented the remaining and standby medicines. This is in agreement with studies conducted by Ocan et al. [1] and Wondimu et al. [9] that pointed out similar findings. However, Jassim [1] indicated that most of the drugs stored in Basra-Iraq are residual drugs $(45 \%)$. Due to the initial overdose of treatment prescriptions, insufficient treatment performance, and anticipated future use, people will retain the remaining medications [21].

\section{Expiration date}

When the drug is stored in the correct conditions, the expiry date is accurate [12]. A suitable condition for storage was identified as refrigeration of the medicines exposed to a oxygenated area and away from kids' reach [1]. By this argument, the participants revealed high percent that they often tested before use on the dates of expiry, while the other householders had no idea about the expiry date of these medicines. Compared to the above findings $(87.5 \%)$ of the participants of koshok et al. study [14] reported checking the expiry date of their medication before use, $55 \%$ of the participants checking their home pharmacy units for expired pharmaceuticals, while 6.9\% of Ali et al. participants [17] confirmed that they did not check the expiry date previously stated. To reduce the health effects of expired drugs a public teaching on the existence and risks of expired drugs, and the disposal of unused drugs is required [12].

\section{Dosage form types}

The main types of home medications mentioned in this study are solid dosage forms (tablets and capsules). These findings consistent with studies performed in Iran $(35.4 \%$ and $24.3 \%$ for tablets and capsules) [15], in the Northern Uganda (70.2 and $13.2 \%$ for tablets and capsules, respectively) [12], and in Northern Palestine were tablets (53.8\%), followed by oral fluid dosages $(13.6 \%)$, and capsules (738\%) [21].

\section{Sharing stored medicines with others}

In terms of sharing stored medicines, about one-third of respondents admitted to sharing their medicines with family or friends, while the other twothirds declined. In contrast, Ali et al. [17] recorded that only more than half $(54.3 \%)$ of respondents shared their medications with friends, family, and/or relatives, while $(37.8 \%)$ did not send them to others. Sharing drugs between people who do not intend to increase the likelihood of unsafe medications may aggravate adverse drug effects, failures of treatment, mortality, and morbidity [10]. The medicines sharing between householders in Iraqi communities reveal the effect of social factors on the use of medicines. 


\section{Conclusion}

The prevalence of storage in households in Diyala - Iraq was high, as all participants kept medicines at home. These drugs are detained regardless of whether they are actually used, and the necessary storage procedures and requirements are rarely followed.

The most frequently stored drugs and also used for self-medication are painkillers and antibacterial agents (without medical consultation). Consequently, pharmacists and health practitioners need to increase the public's consciousness of the effective use of medications, avoidance of residual medicines, which should only be taken after a health professional consultation, proper disposal of remaining products, protection, expiry date, and proper storage.

\section{Recommendations for further works}

Longer and more rigorous studies are needed to determine the exact prevalence and factors related to the storage of medicines at home in other provinces of Iraq.

\section{Acknowledgement}

The authors would like to thank the Diyala pharmacists that contributed in this study.

\section{References}

1. Jassim AM. In-home drug storage and self-medication with antimicrobial drugs in Basrah, Iraq. Oman Med J. 2010;25(2):7987. https://doi.org/10.5001/omj.2010.25 PMid:22125705

2. Abdulsahib WK, Ganduh SH, Radia ND, Jasim LS. New approach for sulfadiazine toxicity management using carboxymethyl cellulose grafted acrylamide hydrogel. Int J Drug Deliv Technol. 2020;10(2):1-7. https://doi.org/10.25258/ijddt.10.2.13

3. Yousif MA. In-home drug storage and utilization habits: A Sudanese study. East Mediterr Health J. 2002;8(2-3):422-31. PMid:15339133

4. Alomar MJ. Factors affecting the development of adverse drug reactions (review article). Saudi Pharm J. 2014;22(2):83-94. https://doi.org/10.1016/j.jsps.2013.02.003 PMid:24648818

5. Kheir N, El Hajj M, Wilbur K, Kaissi R, Yousif A. An exploratory study on medications in Qatar homes. Drug Healthc Patient Saf. 2011;3:99-106. https://doi.org/10.2147/dhps.s25372 PMid:22279414

6. Abdulsahib WK, Ganduh SH, Mahdi MA, Jasim LS. Adsorptive removal of doxycycline from aqueous solution using graphene oxide/hydrogel composite. Int J Appl Pharm. 2020;12(6):100-6. https://doi.org/10.22159/ijap.2020v12i6.39118

7. Mirza N, Ganguly B. Utilization of medicines available at home by general population of rural and Urban set up of Western India. J Clin Diagn Res. 2016;10(8):FC05-9. https://doi.org/10.7860/ jcdr/2016/20600.8298

PMid:27656460

8. Al-Jawad FH, Abdulsahib WK, Al-Attar Z, Al-Hussaini J. Protective effect of cimetidine, isosorbide dinitrate and Vitamin $C$ in experimental model of acute liver injury. Sch Acad J Pharm. 2018;7(7):308-13.

9. Al-Radeef MY. No TitleA comparative study on the knowledge and usage assessment of the over the counter medications among students from Tikrit university. Tikrit $\mathrm{J}$ Pharm Sci. 2017;12(2):14-26.

10. Ocan M, Bbosa GS, Waako P, Ogwal-Okeng J, Obua C Factors predicting home storage of medicines in Northern Uganda. BMC Public Health. 2014;14(1):650. https://doi. org/10.1186/1471-2458-14-650 PMid:24964746

11. Sharif SI, Abduelkarem AR, Bustami HA, Haddad LI, Khalil DS Trends of home drug storage and use in different regions across the Northern United Arab Emirates. Med Princ Pract. 2010;19(5):355-8. https://doi.org/10.1159/000316372 PMid:20639657

12. Wondimu A, Molla F, Demeke B, Eticha T, Assen A, Abrha S, et al Household storage of medicines and associated factors in Tigray Region, Northern Ethiopia. PLoS One. 2015;10(8):e0135650. https://doi.org/10.1371/journal.pone.0135650 PMid:26275057

13. Martins RR, Farias AD, da Oliveira YM, Diniz RD, Oliveira AG Prevalence and risk factors of inadequate medicine home storage: A community-based study. Rev Saude Publica. 2017;51:95. https://doi.org/10.11606/s1518-8787.2017051000053 PMid:29166438

14. Koshok MI, Jan Khairllah T, Al-Tawil SM, Alghamdi EA, Ali AA, Sobh $\mathrm{AH}$, et al. Awareness of home drug storage and utilization habits: Saudi study. Med Sci. 2018;7(1):73-6. https://doi. org/10.5455/medscience.2017.06.8687

15. Foroutan B, Foroutan R. Household storage of medicines and self-medication practices in south-east Islamic Republic of Iran. East Mediterr Health J. 2014;20(9):547-53. https://doi. org/10.26719/2014.20.9.547 PMid:25343467

16. Sawalha A. Extent of storage and wastage of antibacterial agents in Palestinian households. Pharm World Sci. 2010;32(4):530-5. https://doi.org/10.1007/s11096-010-9404-y PMid:20571916

17. Ali SE, Ibrahim MI, Palaian S. Medication storage and selfmedication behaviour amongst female students in Malaysia. Pharm Pract (Granada). 2010;8(4):226-32. https://doi. org/10.4321/s1886-36552010000400004 PMid:25126145

18. Pankajkumar PD, Chacko S, Prakashkumar BS. Storage and disposal of medicines in home among students. J Pharm Res. 2016;10(6):343-50.

19. Al-Radeef MY, Abood SJ, Abdulsahib WK, Hamad So. Comparing the effect of dexamethasone, normal saline, and metoclopramide on prevention of postoperative nausea, vomiting and pain in patient undergoing laparoscopic cholecystectomy or open appendectomy: A randomized clinical trial. Open Access Maced J Med Sci. 2020;8(B):139-44. https://doi.org/10.3889/ oamjms.2020.4095 
20. Abdulsahib WK, Fadhil OQ, Abood SJ. Antimicrobial susceptibility pattern isolated from different clinical samples in Baghdad hospitals. J Adv Pharm Educ Res. 2020;10(1):51-9.

21. Sweileh WM, Sawalha AF, Zyoud SH, Al-Jabi SW, Bani
Shamseh FF, Khalaf HS. Storage, utilization and cost of drug products in Palestinian households. Int J Clin Pharmacol Ther. 2010;48(1):59-67. https://doi.org/10.5414/cpp48059

PMid:20040340

\section{SUPPLYMENTARY}

Table S1: Information about each medicine

\begin{tabular}{|c|c|c|c|c|c|c|c|c|}
\hline $\mathrm{S} / \mathrm{N}$ & $\begin{array}{l}\text { Therapeutic } \\
\text { categories }\end{array}$ & Dosage form & $\begin{array}{l}\text { Drugs prescribed } \\
\text { by }\end{array}$ & $\begin{array}{l}\text { Usage status of currently } \\
\text { sored medicine }\end{array}$ & $\begin{array}{l}\text { Sharing of } \\
\text { medication }\end{array}$ & Source of drugs & Expiry date & Storage place \\
\hline & $\begin{array}{l}\text { Write name } \\
\text { of drug and } \\
\text { its category }\end{array}$ & $\begin{array}{l}1=\text { tablet } \\
2=\text { capsule } \\
3=\text { drop } \\
4=\text { syrup } \\
5=\text { ampule/vial } \\
6=\text { suppository }\end{array}$ & $\begin{array}{l}1=\text { doctors } \\
2=\text { pharmacist } \\
3=\text { self-prescribed } \\
4=\text { relative/friends }\end{array}$ & $\begin{array}{l}1=\text { in current use } \\
2=\text { lef to ver } \\
3=\text { standby }\end{array}$ & $\begin{array}{l}1=\text { yes } \\
2=\text { no } \\
\text { Yes, share with others } \\
\text { No, not shared }\end{array}$ & $\begin{array}{l}1=\text { pharmacies } \\
2=\text { health centers } \\
3=\text { relatives } / \text { friends } \\
4=\text { others }\end{array}$ & $\begin{array}{l}1=\text { expired } \\
2=\text { not- expired } \\
3=\text { not known }\end{array}$ & $\begin{array}{l}1 \text { = refrigerator, } \\
2=\text { kitchen } \\
\text { counters } \\
3=\text { bathroom } \\
4=\text { bed/living room }\end{array}$ \\
\hline $\begin{array}{l}1 \\
2 \\
3 \\
4 \\
5 \\
6\end{array}$ & & & & & & & & \\
\hline
\end{tabular}

\section{Questionnaire}

Questionnaire used to assess the presence of medicines in households and their utilization.

\section{Part I: Socio-demographic information}

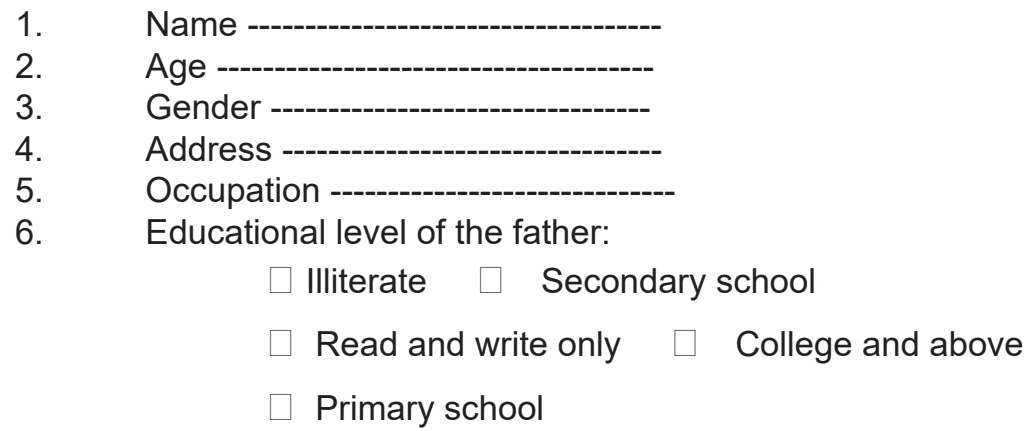

7. Community
Urban
Rural

Part II. Information on medicines available in the households (currently used or left-over)

1. Do you have any medicines available at home today?
Yes
No

2. Can I please see all of them? Write one medicine per row, and use codes provided in each column to collect information about each medicine.

1

2 